\title{
(2) OPEN ACCESS \\ Are young military personnel at a disproportional risk of heat illness?
}

\author{
Henry B Ogden (1), ' A J Rawcliffe, ${ }^{1}$ S K Delves, ${ }^{2}$ A Roberts ${ }^{1}$
}

${ }^{1}$ Army Recruit Health and Performance Research, UK Ministry of Defence, Upavon, UK ${ }^{2}$ Environmental Medicine and Science, Institute of Naval Medicine, Gosport, UK

\section{Correspondence to} Dr Henry B Ogden, UK Ministry of Defence, HQ Army Recruiting and Initial Training Command, Upavon, UK; henry.ogden100@ mod.gov.uk

Received 26 November 2021 Accepted 8 January 2022

\section{Check for updates}

(c) Author(s) (or their employer(s)) 2022. Re-use permitted under CC BY-NC. No commercial re-use. See rights and permissions. Published by BMJ.

\section{To cite: Ogden $\mathrm{HB}$,}

Rawcliffe AJ, Delves SK, et al. BMJ Mil Health Epub ahead of print: [please include Day Month Year]. doi:10.1136/ bmimilitary-2021-002053

\section{ABSTRACT}

Heat illnesses (HI) define a continuum of conditions where patients become incapacitated due to uncompensable heat stress. In the military, $\mathrm{HI}$ has a significant health, financial and operational burden that requires vigilant management. Military training and operations regularly expose personnel to known $\mathrm{HI}$ risk factors, meaning that prevalence remains high despite stringent attempts to reduce risk to as low as reasonably practicable. While prepubertal children and elderly adults are widely demonstrated to be at greater risk of classic $\mathrm{HI}$ than young adults due to impaired physiological and/ or behavioural thermoregulation, in military personnel, it is young recruit-age individuals (16-19 years) who consistently experience the highest prevalence of exertional HI. Mechanistically, controlled laboratory studies have never directly compared thermoregulation between young recruit-age individuals and other groups of adults, though research highlighting impaired thermoregulation in prepubertal children potentially has some relevance to late-developing young recruit-age personnel. Aside from potential age-related differences in thermoregulation, a major consideration must also be given to the increased prevalence of organisational risk factors for $\mathrm{HI}$ in younger military personnel (eg, education, physical load, rank, job roles), which is likely to be the primary explanation behind age-related trends in $\mathrm{HI}$ prevalence, at least in the military. The aims of this article are to review: (i) the epidemiology of $\mathrm{HI}$ between young recruit-age individuals and older military personnel; (ii) the theoretical basis for ageassociated differences in thermoregulatory function and (iii) pertinent areas for future research.

\section{INTRODUCTION}

Humans aim to maintain core body temperature $\left(\mathrm{T}_{\text {core }}\right)$ around a set-point of $37.0^{\circ} \mathrm{C} \pm 1.0^{\circ} \mathrm{C} .{ }^{1}$ Attaining thermal equilibrium relies on both behavioural (eg, seeking shade, modifying body orientation) and autonomic (eg, sweating, blood flow redistribution) responses that regulate bidirectional heat transfer with the environment. ${ }^{1}$ In most land-dwelling circumstances encountered by humans, these thermoregulatory processes are highly effective. However, the development of heat illness (HI) can be rapid if the compensatory limits for heat dissipation are exceeded, either due to high environmental heat stress (classic heat illness $(\mathrm{CHI})$ and/or sustained vigorous physical activity (exertional heat illness (EHI)). ${ }^{2}$ Despite anecdotal records of HI dating back millennia, a universal medical definition is still lacking, with most classifications describing a broad continuum of progressively severe conditions where patients become
Key messages

- Heat illness (HI) remains prevalent in the military despite stringent attempts to reduce the risk to as low as reasonably practicable.

- Young recruit-age individuals (16-19 years) are more susceptible to $\mathrm{HI}$ than older adults and might warrant additional risk mitigation.

- Why $\mathrm{HI}$ is more prevalent in young recruitage individuals is poorly defined, though it is likely to be primarily driven by differences in exposure to organisational risk factors (eg, physical load, military rank, education, selection courses), rather than differences in adult-child physiology.

- Future research is required to clarify the independent influence of age on $\mathrm{HI}$ prevalence in the military when accounting for relevant organisational and physiological risk factors.

incapacitated following uncompensable heat stress. ${ }^{2}$ These include relatively mild conditions like heat exhaustion, where $T_{\text {core }}$ is said to be increased but $<40^{\circ} \mathrm{C}$ without central nervous system dysfunction; and more severe conditions such as heat stroke where $\mathrm{T}_{\text {core }}$ is increased $>40^{\circ} \mathrm{C}$ with evidence of central nervous system dysfunction. ${ }^{3}$

Military training and operations present an environment where personnel are frequently exposed to well characterised physical (eg, low fitness, febrile illness), behavioural (eg, dehydration, excessive motivation) and environmental (eg, high ambient temperature/humidity, non-permeable clothing) risk factors for $\mathrm{HI}$ diagnosis. ${ }^{45}$ Although international military policies outline stringent recommendations to reduce the risk of $\mathrm{HI}$ to as low as reasonably practicable, ${ }^{6}$ annual prevalence of severe HI (ie, heat stroke) has remained between 50 and 700 cases per 100000 personnel in both the $\mathrm{UK}^{78}$ and $\mathrm{US}^{910}$ Armed Forces over recent years. Of these cases, the vast majority ( $95 \%)$ occurred during arduous physical exertion (ie, EHI) and many outside of the warmer summer months. $\mathrm{HI}$ is a pertinent problem to the military, that has a substantial health (eg, medical discharge, reduced life expectancy), financial (eg, medical treatment, sick leave, compensation) and operational (eg, recruit wastage, casualty evacuation, increased risk of other military hazards) burden. ${ }^{11} 12$ Furthermore, given global predictions of increased wet bulb globe temperature and more frequent extreme weather events, the threat of $\mathrm{HI}$ is only anticipated to worsen in future. ${ }^{11}$ 
Biological age is a potential multifaceted risk factor for HI. Historically, prepubertal children $(<12 \text { years })^{13}$ and elderly adults ( $>65$ years) ${ }^{14}$ have been widely documented to be the most susceptible age-groups to $\mathrm{CHI}$. This heightened vulnerability is said to be attributable to impaired physical mobility and/or lesser knowledge of the risks associated with $\mathrm{HI}$ that govern aptitude to adjust behaviour under environmental heat stress (eg, seeking shade); alongside a lower capacity for heat dissipation (eg, lower sweat rate). ${ }^{2}$ In comparison, EHI predominately transpires in highly motivated young adults employed in occupations that involve arduous physical activity and often where social constructs reduce likelihood of removal from the high-risk environment (eg, military deployment, emergency first response, sports competition). ${ }^{2}$ Given that EHI is purported to be driven by increased risk exposure, rather than age-associated thermoregulatory or behavioural impairments, the relevance of biological age on EHI risk has received little direct research attention. However, a growing body of recent epidemiological evidence conducted in both military and civilian settings consistently reports that young recruit-age individuals (16-19 years) in fact experience disproportionally higher rates of EHI than older peers (20-40 years). To inform future military $\mathrm{HI}$ policy surrounding appropriate risk mitigation in young recruit-age individuals so as to neither neglect vulnerabilities or hinder those who do not require extra protection, this article will review: (i) the epidemiology of $\mathrm{HI}$ between young military recruit-age individuals and older adults; (ii) the theoretical basis for age-associated differences in thermoregulatory function and behaviour and (iii) pertinent areas for future research, including methodological considerations.

\section{Epidemiology \\ US Military}

The US Military Health System publishes within the Medical Surveillance Monthly Report (MSMR) annual HI prevalence data of defence medical records for individuals serving in the active component of the US Army, Navy, Air Force and Marine Corps. ${ }^{9} 10$ This comprehensive dataset includes all ambulatory encounters and hospitalisations for $\mathrm{HI}$ diagnosis using International Classification of Disease criteria that occurred at any military or civilian medical facility worldwide. For surveillance purposes, absolute incidence and relative prevalence is categorised by various demographic (eg, sex, ethnicity) and military (eg, service, occupation, home station) characteristics, including age group ( $<20$ years; $20-24$ years; $25-29$ years; $30-34$ years; $35-39$ years; $>40$ years). These data year-on-year demonstrate a decline in both heat exhaustion (Figure 1A) and heat stroke prevalence with increasing age (Figure 1B). Between years 2010 and 2020, the overall mean heat exhaustion and heat stroke prevalence was $5.3 \%$ and $0.7 \%$ in $<20$ years; $2.0 \%$ and $0.4 \%$ in $21-24$ years; $1.2 \%$ and $0.3 \%$ in $25-29$ years; $0.7 \%$ and $0.2 \%$ in $30-34$ years; $0.4 \%$ and $0.1 \%$ in $35-39$ years and $0.4 \%$ and $0.1 \%$ in $>40$ years, respectively. ${ }^{910}$

In accordance with the US Military Health System database, a retrospective cohort analysis of all $\mathrm{HI}$ incidents held on the Standard Military Data Repository was published for the years 2011 to $2014(\mathrm{n}=238,168){ }^{15}$ This database records all health encounters of US Army soldiers, however, only recent enlistees who commenced service and experienced a mild (ie, heat exhaustion) or severe (ie, heat stroke) HI during the study period were included within the analysis. In total, 2612 incidents of mild HI and 732 incidents of severe HI events were reported, which affected $1.1 \%$ and $0.3 \%$ of the study population,
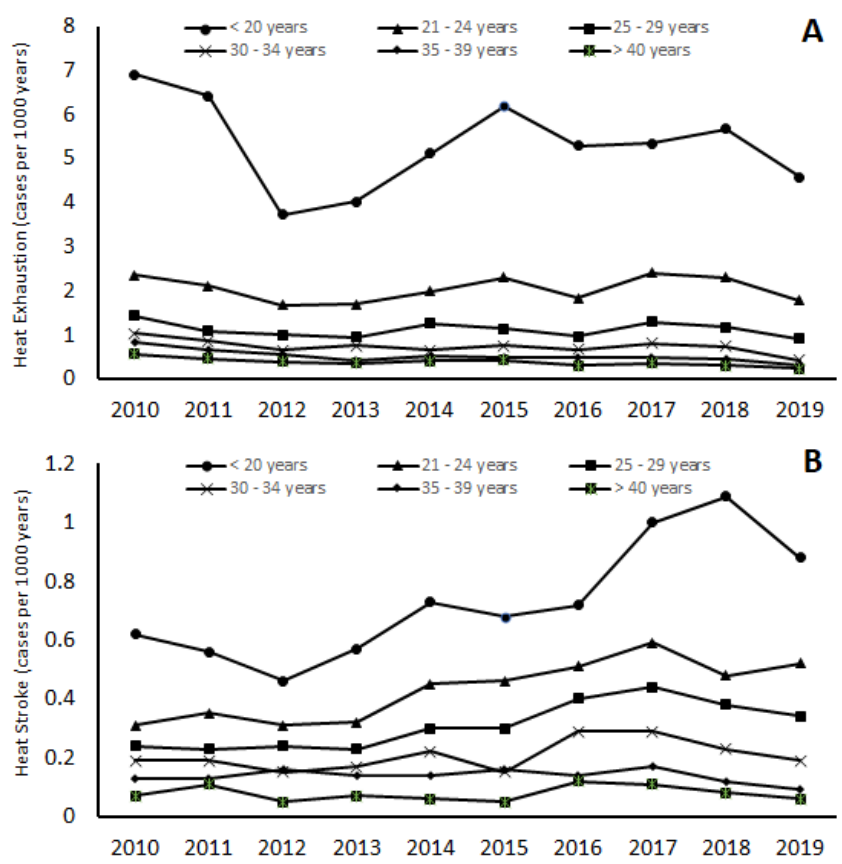

Figure 1 Prevalence of heat exhaustion (A) and heat stroke (B) in the active component of the US Army, Navy, Air Force and Marine Corps $(2010-2020)^{910}$

respectively. The prevalence of mild HI decreased with age from $2.2 \%$ in $\leq 20$ years $(2.2 \%), 0.9 \%$ in $21-22$ years, $0.7 \%$ in $23-24$ years and $0.7 \%$ in $\geq 25$ years $(p<0.01) .{ }^{15}$ Likewise, though less prevalent, severe $\mathrm{HI}$ also decreased with age from $0.5 \%$ in $\leq 20$ years, $0.3 \%$ in $21-22$ years, $0.3 \%$ in $23-24$ years and $0.2 \%$ in $\geq 25$ years. In addition to descriptive statistics, this study applied a multivariable discrete-time logistic regression model to control for other important HI risk factors, namely: sex, ethnicity, body mass index, fitness, pay grade, marital status, medications, length of military service, prior HI and entry aptitude score. Data are presented as OR and 95\% CI. This analysis determined that age $\leq 20$ years independently increased the risk of mild (1.23 (1.08 to 1.40$)$ ), but not severe (0.89 (0.71 to 1.12$)$ ) $\mathrm{HI}$, in comparison aged $\geq 25$ years. Importantly, stage of recruit training $<4$ months (mild $\mathrm{HI}=2.97$ (2.60 to 3.39 ); severe $\mathrm{HI}=1.79(1.41$ to 2.26$)$ ) and low aptitude score on enlistment (mild $\mathrm{HI}=1.26$ (1.12 to 1.42 ); severe $\mathrm{HI}=1.04$ (0.84 to $1.30)$ ), risk factors closely associated with young age, were both stronger predictors of mild and severe HI than age itself.

\section{UK Military}

The UK Ministry of Defence Joint Service Publication on HI prevention (JSP 375) directs military commanders to report all suspected and diagnosed HI cases to the Defence Accident Investigation Branch in accordance with top-level budget authority. Where reported, HI cases are instructed to be escalated to unit medical centres through the chain of command to ensure appropriate medical follow-up and recording takes place. This dual mechanism of command and medical notification has facilitated some epidemiological analysis of HI across the UK Military; however, this reporting has been widely stated to suffer from poor compliance and inconsistent taxonomies that limit data accuracy. ${ }^{816}$ Furthermore, contrasting to the US Military MSMR, $\mathrm{HI}$ incidence in the UK military is not routinely examined by unique patient demographics, such as biological age. In 2016, 
the most comprehensive analysis of $\mathrm{HI}$ prevalence in the UK military was published, which retrospectively analysed all British Army HI cases identified across command and medical notification databases between 1 January 2009 and 31 December $2013 .{ }^{8}$ Though this publication did not provide age-specific subgroup analysis, comparisons were made between full-time and recruit populations, who, by virtue of standard entry and retirement ages, could be considered to represent a young and older demographic. Over the 5 -year study period, the mean annual HI prevalence was circa 2.5 -fold greater in recruits $(0.22 \%)$, compared with fully-trained $(0.09 \%)$ personnel. ${ }^{8}$ While these statistics provide some indication of an increased risk of $\mathrm{HI}$ in younger recruit aged individuals, they do not account for biases in reporting taxonomy or inconsistencies in the quality of data reporting between military establishments. For example, it is anecdotally understood that awareness of, and compliance with, HI reporting is better across military basic training establishments than on deployments, due to factors including a greater expectation to model best practise and the general appointment of more senior medical/training staff who may better reinforce reporting guidance.

\section{Civilian endurance races}

There is emerging evidence from civilian warm-weather endurance races that young-recruit aged individuals are more susceptible to HI than adults. A 15-year retrospective analysis of all exertional heat stroke (EHS) cases requiring medical triage from the Falmouth (USA) summer 7-mile running road race, included a total of 155072 competitors between 2003 and 2018 (excluding age-classifications in 2006), with 343 suspected EHS casualties. Participants aged 15-18 years had the highest prevalence of $\mathrm{HI}$ of any age-classification $(0.40 \%$ of entrants), in comparison with $<14$ years $(0.24 \%), 19-39$ years $(0.21 \%)$ and $30-49$ years $(0.25 \%) .{ }^{17}$ Similarly, when considering sex, age and wet-bulb global temperature within a multivariate linear regression model, $<14$ years $(\beta=2.41, \mathrm{p}=0.008), 15-18$ years $(\beta=3.83, p<0.001)$ and $19-39$ years $(\beta=2.24, p=0.014)$ were the only factors that accounted for an increased risk of EHS. It is noteworthy to consider that in this study, the average race times were comparable between each age classification of EHS collapses (52-62 min), indicating that overall risk exposure and fitness demographics are likely comparable, although differences in pacing behaviour cannot be dismissed. A limitation of this study was the use of the race's non-uniform age classifications (eg, 15-18 years, 19-39 years) that complicates the identification of young-age as a risk factor for HI.

\section{Thermoregulatory mechanisms}

Controlled laboratory studies have evaluated the influence of age on whole-body thermoregulatory and cardiovascular responses to fixed-intensity exertional heat stress. However, relevant research has focused exclusively on prepubertal children ${ }^{13}$ or elderly adults, ${ }^{14}$ with no study directly examining thermoregulation in young recruit-aged individuals. In comparison to young adults, prepubertal children have long been thought to have compromised thermoregulation that makes them more vulnerable to $\mathrm{HI}$, which might have relevance to late maturing military recruits aged 16-19 years. The notion that prepubertal children have impaired thermoregulation is a widespread belief based on seminal papers from the 1980s theorising several childadult physiological differences that could modulate certain biophysics of thermoregulation. ${ }^{13}$ These differences include: (1) body morphology; (2) cutaneous vasodilation; (3) sweat rate; (4) gait mechanical efficiency and (5) thermal sensation. Overall, it appears the impact of these biophysical differences on heat strain is likely context dependant.

\section{Body morphology}

The human body stores heat faster with lower mass and exchanges more heat with greater surface area; both storage and exchange are affected by body composition. ${ }^{1}$ Young recruit-aged individuals yet to reach maturation typically have a smaller body mass, but greater relative surface area than fully developed adults. ${ }^{13}$ This means that military personnel yet to reach physical maturation will store heat faster than fully developed adults when exposed to an identical heat load; however, they will also dissipate a greater proportion of heat back to the environment where skin temperature is warmer than environmental temperature. ${ }^{13}$ Differences in the thermal properties (heat capacity, conductivity and density) of tissue between deep-body structures and the skin (primarily muscle and adipose) will also alter heat transfer to the environment. ${ }^{1}$ Due to higher density and thermal conductivity, but lower heat specific capacity, muscle tissue stores heat faster than adipose tissue. This means that individuals with lower relative skeletal muscle mass dissipate heat less efficiently, which theoretically explains why low body mass index $\left(\leq 18.5 \mathrm{~kg} \mathrm{~m}^{2}\right)$ is a strong predictor of $\mathrm{HI}$ in military populations. ${ }^{15}$ However, this factor cannot be considered a mechanism why recruit-age individuals are more susceptible to $\mathrm{HI}$ than young adults given that relative skeletal muscle mass plateaus after age of 14 years. ${ }^{18}$

The influence of body morphology on child-adult differences in thermoregulation was elegantly demonstrated by Leites et al. ${ }^{19}$ In this study, prepubertal boys (10-12 years) and young men (19-25 years) matched for aerobic fitness and \% body fat, undertook two separate cycling heat tolerance tests prescribed to elicit either a fixed absolute metabolic heat production or a fixed metabolic heat production corrected for body mass. During exercise prescribed to produce the same absolute metabolic heat, prepubertal boys stored more heat than young men ( $\Delta$ core temperature $=0.6 \pm 0.2$ vs $0.3^{\circ} \mathrm{C} \pm 0.2^{\circ} \mathrm{C}$ ) due to their lighter mass. However, when metabolic heat production was prescribed relative to body mass, heat storage was not influenced by age ( $\Delta$ core temperature $=0.6 \pm 0.2$ vs $0.7^{\circ} \mathrm{C} \pm 0.2^{\circ} \mathrm{C}$ ). These results could not be attributed to between-group differences in either mechanical efficiency or the evaporative heat balance requirement, highlighting the importance of body morphology on heat storage.

\section{Gait mechanical efficiency}

Metabolic heat production is the principal driver of heat storage during exertional heat stress. ${ }^{1}$ Human movement is relatively inefficient, with $<20 \%$ of metabolic energy being used to perform external work. ${ }^{1}$ The remaining energy is lost as heat that is either stored within the body or dissipated to the environment. Subsequently, individuals with inefficient gait commonly produce 20\%-30\% more metabolic heat than more efficient individuals of similar fitness and body composition when working at the same exercise intensity. ${ }^{20}$ It is well established that prepubertal children produce more metabolic heat during matched absolute intensity upright locomotion (running and walking) than adults due to their shorter stature, which subsequently results in a reduced stride-length and increased stridefrequency. ${ }^{21-23}$ The potential importance of poor mechanical efficiency on thermoregulation during upright locomotion is demonstrable given that young adults and children have comparable thermoregulation in response to cycling where mechanical 
efficiency is similar, ${ }^{23} 24$ walking with intensity prescribed relative to stature ${ }^{25}$ and running with intensity prescribed relative to metabolic heat production. ${ }^{19}$ Based on the UK90 height data, the average man is within $3 \%(4 \mathrm{~cm})$ of adult stature and average woman within $1 \%$ of adult stature $(1 \mathrm{~cm})$ at 16 years old. ${ }^{26}$ This suggests the influence of age on mechanical efficiency that is attributable to stature is negligible in most individuals of military enlistment age during upright locomotion.

\section{Sweat rate}

Attenuated sweat production, resulting in reduced evaporative heat loss, has historically been considered the key factor of why prepubertal children experience greater heat strain than adults during both passive and exertional heat stress. ${ }^{13}$ The reason for reduced sweat production in prepubertal children can be attributed to their smaller sweat gland size, despite the fact that they have a greater gland density per unit surface area than adults. ${ }^{27}$ In addition to sweat production, sweat composition also influences evaporative heat loss. Where sweat is more dilute after reabsorption of electrolytes at the sweat gland, sweat evaporates more readily from the skin surface due to its lower latent heat of vaporisation. There is some evidence that children's sweat is more dilute than adults, ${ }^{28}$ thus promoting more efficient heat loss per volume of sweat.

A key question for EHI risk is whether age-related differences in sweat rate are associated with changes in core body temperature. In prepubertal (12.2 \pm 0.3 years), mid-pubertal (13.6 \pm 0.4 years) and late-pubertal $(16.7 \pm 0.6$ years $)$ men matched for fitness and body composition, sweat rate increased with age during low intensity cycling in hot-dry heat $\left(40^{\circ} \mathrm{C} ; 20 \%\right.$ relative humidity) ${ }^{29}$ However, core body temperature was unaffected by age in this study despite evaporative heat loss being the primary mechanism for heat dissipation in hot-dry environments. A limitation of this study was that exercise was prescribed based on relative aerobic capacity, meaning that the benefits of increased sweat production in older children were likely somewhat negated by and due to working at a greater absolute metabolic heat production. However, despite this limitation, other studies have shown that prepubertal children and adults have comparable evaporative heat loss when exposed to identical heat strain, despite vastly different sweat rates. ${ }^{19} 29$ Overall, these results suggest that the increase in sweat rate across puberty likely has a negligible influence on heat strain. Finally, in circumstances where relative humidity is high, either due to the ambient environment or from wearing occlusive clothing, sweat rate often exceeds the maximal rate of evaporation possible, thus negating any potential influence. ${ }^{1}$

\section{Cutaneous vasodilation}

Cutaneous vasodilation supports heat transfer between deep metabolically active tissue and the environment. Despite limited research, prepubertal children typically respond faster and have greater absolute cutaneous blood flow than young adults under matched heat strain. ${ }^{29-32}$ For example, during 1-hour lower-limb hot-water immersion $\left(42^{\circ} \mathrm{C}\right)$ that evoked comparable heat strain between prepubertal children (7-11 years) and young adults (21-25 years), skin blood flow was markedly greater in prepubertal children on the back and chest. ${ }^{29}$ To facilitate the elevation in cutaneous vasodilation, cardiac output must increase beyond the ability to support metabolic demands. However, because prepubertal children possess comparable cardiac output to adults, ${ }^{13}$ this means that they must redistribute a greater proportion of cardiac output away from either the skeletal muscle or splanchnic vasculature (eg, gut, kidney, liver, spleen) to enhance cutaneous blood flow. ${ }^{1}$ These responses have potential clinical relevance given that reduced skeletal muscle perfusion increases the relative metabolic demand of exercise. If exercise intensity is sustained, reliance on carbohydrate metabolism is increased, which generates more metabolic heat than fat metabolism and accelerates heat storage. ${ }^{33}$ Histamine is a key modulator of skeletal muscle vasodilation that is released during exercise proportional to skeletal muscle mass, which might provide a mechanism to explain why prepubertal children yet to reach physical maturation have increase cutaneous vasodilation than adults during exertional heat stress. ${ }^{34}$ Reduced splanchnic perfusion to facilitate cutaneous blood flow increases gut barrier permeability via ischaemia-reperfusion injury, which is a key upstream event in the gastrointestinal EHS paradigm, whereby gut microbial translocation induces systemic inflammation that is predictive of poor clinical outcome from EHS. ${ }^{35}$

\section{Thermal perception}

Behavioural thermoregulation is limitless in capacity to optimise the conditions for environmental heat transfer. ${ }^{34}$ Numerous examples of thermal behaviours are readily identifiable, such as altering body orientation/position, microenvironment selection (eg, seeking shade, clothing, air conditioning) and exercise pacing. Thermal perception is pivotal to understanding willingness to adjust behaviours that influence thermoregulation. During exertional heat stress, rating of perceived exertion (RPE) is believed to the best predictor of exercise pacing and volitional exhaustion. $^{36}$

To date, few studies have examined the influence of young age on RPE in response to exertional heat stress. In prepubertal ( $n=10 ; 12.2 \pm 0.3$ years $)$, mid-pubertal $(n=13 ; 13.6 \pm 0.4$ years $)$ and late-pubertal $(n=8 ; 16.7 \pm 0.6 y)$ men matched for fitness and body composition, late-pubertal males gave the lowest of cycling in the heat, despite having an increased skin temperature, core temperature and rate of heat storage. ${ }^{29}$ This finding is supported by Bergeron $e t a l^{37}$ who reported that older junior athletes (16-17 years) had a lower RPE throughout 80 min exertional heat stress than younger aerobic fitness-matched junior athletes (12-13 years) when heat strain was comparable. Other authors have also reported that prepubertal children have lower RPE and greater thermal sensation and discomfort than adults in response to comparable heat strain. ${ }^{19}$ Together, these data suggest that younger recruit-age individuals are less able to sense physical exertion under heat strain than prepubertal children and thus are less likely to modify their behaviour (eg, pacing) when under heat stress. ${ }^{35}$ Direct research comparing thermal sensation and RPE between young recruit-age individuals and older adults under identical heat strain has never been undertaken.

\section{Future research}

\section{Epidemiological field studies}

Traditional risk factors for $\mathrm{HI}$ in the military are generally categorised as either environmental (eg, warm ambient environment, lack of heat acclimation, inappropriate clothing, disturbed sleep, military rank), physical (eg, ethnicity, sex, low physical fitness, higher body fat) or behavioural (eg, dehydration, poor nutrition, motivation, aptitude). ${ }^{45}$ While biological age could be considered a physical HI risk-factor in its own entity, it is unclear whether the enhanced prevalence of HI in young recruit-aged individuals is in fact attributable to increased exposure to other confounding $\mathrm{HI}$ risk factors, or methodological bias due to better medical reporting of cases by military training establishments. ${ }^{11}$ 
For example, psychological states such as high intrinsic motivation to reach extreme performance goals (eg, pass a criterion task), or increased exposure to extrinsic motivators (eg, response to authority due to military rank, embarrassment), are typically more pronounced in personnel at the beginning of their military career. An increase in motivation may predispose young recruits to $\mathrm{HI}$ if they are less willing to moderate exercise intensity or terminate exercise by ignoring autonomic physiological cues. ${ }^{38}$ Younger personnel also have less military experience than older personnel at a population level, meaning that they are less likely to be fully coherent with military policy to ensure educated decisions are made to minimise personal risk. ${ }^{15}$ To account for this variability in risk exposure, future prospective research should look to examine the independent influence of age on HI prevalence when accounting for other traditional (eg, sex, ethnicity, fitness, body composition, sleep quality) and novel (eg, motivation, military experience, aptitude) $\mathrm{HI}$ risk factors, including those recently outlined by Westwood et al. ${ }^{4}$ Ideally, this research should be conducted on a distinct military population (eg, trained vs untrained, service unit, job role) and during a specific event (eg, criterion fitness test, location of service, season) to minimise between-subject heterogeneity.

\section{Laboratory studies}

From a theoretical standpoint, several physiological and behavioural differences exist that could make young-recruit aged individuals more susceptible to HI than their older peers, especially in those individuals yet to reach physical maturation. However, presently there is an absence of research directly comparing basic thermoregulatory responses between young recruit-age individuals and adults in response to exertional heat stress. To move towards more valuable age-associated comparisons in HI risk, future research should account for important methodological issues historically plaguing research examining the influence of age on thermoregulation.

First, to minimise bias when comparing morphologically heterogeneous populations, size-dependent physiological data should be normalised ratiometrically by correcting data to an appropriate anthropometric characteristic. As previously recommended by Notley et $a l^{13}$ for performing unbiased child-adult comparisons, prescribing exercise relative to area-specific metabolic heat production $\left(\mathrm{W} \mathrm{m}^{-2}\right)$ is the most appropriate methodology to ensure that the relative heat loss requirement is equal. Second, given that age-associated differences in physiological thermoregulation may be contingent on the magnitude of heat strain elicited, it is important to compare responses in a wide variety of ambient environments and across multiple relevant work intensities/durations. Third, the summative effects of combined interindividual (eg, sex, ethnicity) and intraindividual (eg, body composition, aerobic fitness, heat acclimation status) factors on thermoregulation should be examined and accounted for statistically. For example, pronounced hypohydration reduces sweat production and could potentially negate the influence of maturation on sweat rate. Fourth, for appropriate thermo-behaviour comparisons, it is important to disassociate the independent influences of age and heat strain. This can be accomplished by examining thermal perception at fixed increments in core body temperature, rather than after a predetermined time period. ${ }^{35}$ Fifth, although most military HI cases occur during group-paced (eg, marching, collective load carriage) or group-timed (eg, role fitness test) exercise, ${ }^{39}$ it is important to consider whether recruit-age individuals have an altered ability to voluntarily reduce exercise-intensity to protect thermoregulation during competitive self-paced exercise. Such a study could compare the separate influences of age and military experience on exercise pacing in the heat during head-to-head competition, where perceived and actual thermophysiological state are tightly associated with certain psychological trait-like (eg, risk taking behaviour) and state characteristics (eg, positive affect). ${ }^{40}$ Finally, gastrointestinal barrier integrity, microbial translocation and systemic cytokinemia are hypothesised key pathophysiological events in the development of severe $\mathrm{HI}$, though changes in these measures during adolescence and young-adulthood are unknown. ${ }^{34}$

\section{CONCLUSION}

Overall, $\mathrm{HI}$ appears more prevalent in young recruit-age individuals (16-19 years) than young adults (21-39 years) in both military personnel and civilian sports events. Despite this evidence, it is unclear whether this trend is primarily attributable to differences in: (1) surveillance, given that compliance with HI reporting is generally better in recruit populations; (2) physiology, such as body morphology, active heat transfer pathways and thermal behaviour or (3) exposure to known organisational HI risk factors (eg, fitness, exercise load, education, motivation). Presently, there is little empirical evidence to directly support any of these mechanisms, though it is urgently recommended that field studies using appropriate methodologies are undertaken to clarify the independent influence of age on $\mathrm{HI}$ prevalence when accounting for important confounding factors, such as military experience/rank, aptitude, training load and body composition. Likewise, laboratory-controlled trials should explore the mechanistic basis for any age-associated differences in physiological or behavioural responses to exertional heat stress, though it is hypothesised that responses between young-recruit age individuals and adults are likely to be negligible.

Twitter Henry B Ogden @OgdenHenry and A Roberts @andyroberts1234

Collaborators None.

Contributors $H B O$ and $A R$ wrote the manuscript. $H B O, A J R, S D$ and $A R$ reviewed and approved the final version of the manuscript.

Funding The authors have not declared a specific grant for this research from any funding agency in the public, commercial or not-for-profit sectors.

Competing interests None declared.

Patient consent for publication Not applicable.

Provenance and peer review Not commissioned; externally peer reviewed.

Data availability statement No data are available. Not Applicable.

Open access This is an open access article distributed in accordance with the Creative Commons Attribution Non Commercial (CC BY-NC 4.0) license, which permits others to distribute, remix, adapt, build upon this work non-commercially, and license their derivative works on different terms, provided the original work is properly cited, appropriate credit is given, any changes made indicated, and the use is non-commercial. See: http://creativecommons.org/licenses/by-nc/4.0/.

\section{ORCID iD}

Henry B Ogden http://orcid.org/0000-0001-7827-0922

\section{REFERENCES}

1 Cramer MN, Jay 0. Biophysical aspects of human thermoregulation during heat stress. Auton Neurosci 2016;196:3-13.

2 Epstein Y, Yanovich R. Heatstroke. N Engl J Med Overseas Ed 2019;380:2449-59.

3 Bouchama A, Knochel JP. Heat stroke. N Engl J Med Overseas Ed 2002;346:1978-88.

4 Westwood CS, Fallowfield JL, Delves SK, et al. Individual risk factors associated with exertional heat illness: a systematic review. Exp Physiol 2021;106:191-9.

5 Alele FO, Malau-Aduli BS, Malau-Aduli AEO, et al. Epidemiology of exertional heat illness in the military: a systematic review of observational studies. Int J Environ Res Public Health 2020;17:7037.

6 Parsons IT, Stacey MJ, Woods DR. Heat adaptation in military personnel: mitigating risk, maximizing performance. Front Physiol 2019;10:1485. 
7 Dickinson JG. Heat illness in the services. BMJ Military Health 1994;140:7.

8 Stacey MJ, Brett S, Woods D. Case ascertainment of heat illness in the British Army: evidence of under-reporting from analysis of medical and command notifications, 2009-2013. BMJ Military Health 2016;162:428-33.

9 Armed Forces Health Surveillance Center. Update: heat illness, active component, us. armed forces, 2014. MSMR 2015;22:17-20 https://www.bu.edu/sph/files/2019/02/ MSMR-2018-Heat-illness-active-component.pdf

10 Armed Forces Health Surveillance Center. Update: heat illness, active component, us. armed forces, 2020. MSMR 2021;22:17-20 https://www.health.mil/News/Articles/ 2021/04/01/Update-Heat-MSMR-2021

11 Taylor N, Stacey MJ, Smith M, et al. Exertional heat illness in the military: a voice from the past with lessons for the present. BMJ Mil Health 2020;166:285-6.

12 Wallace RF, Kriebel D, Punnett L, et al. Prior heat illness hospitalization and risk of early death. Environ Res 2007;104:290-5.

13 Notley SR, Akerman AP, Meade RD, et al. Exercise thermoregulation in prepubertal children: a brief methodological review. Med Sci Sports Exerc 2020;52:2412-22.

14 Meade RD, Akerman AP, Notley SR, et al. Physiological factors characterizing heatvulnerable older adults: a narrative review. Environ Int 2020;144:105909.

15 Nelson DA, Deuster PA, O'Connor FG, et al. Timing and predictors of mild and severe heat illness among new military enlistees. Med Sci Sports Exerc 2018;50:1603-12.

16 Stacey M, Woods D, Ross D, et al. Heat illness in military populations: asking the right questions for research. J R Army Med Corps 2014;160:121-4.

17 Belval LN, Giersch GEW, Adams WM, et al. Age- and Sex-Based differences in exertional heat stroke incidence in a 7-Mile road race. J Athl Train 2020;55:1224-9.

18 McCarthy HD, Samani-Radia D, Jebb SA, et al. Skeletal muscle mass reference curves for children and adolescents. Pediatr Obes 2014:9:249-59.

19 Leites GT, Cunha GS, Obeid J, et al. Thermoregulation in boys and men exercising at the same heat production per unit body mass. Eur J Appl Physiol 2016;116:1411-9.

20 Smoljanić J, Morris NB, Dervis S, et al. Running economy, not aerobic fitness, independently alters thermoregulatory responses during treadmill running. J App/ Physiol 2014;117:1451-9.

21 Wagner JA, Robinson S, Tzankoff SP, et al. Heat tolerance and acclimatization to work in the heat in relation to age. J Appl Physiol 1972;33:616-22.

22 Unnithan VB, Eston RG. Stride frequency and submaximal treadmill running economy in adults and children. Pediatr Exerc Sci 1990;2:149-55.

23 Rowland TW, Staab JS, Unnithan VB, et al. Mechanical efficiency during cycling in prepubertal and adult males. Int I Sports Med 1990;11:452-5.

24 Shibasaki M, Inoue Y, Kondo N, et al. Thermoregulatory responses of prepubertal boys and young men during moderate exercise. Eur J Appl Physiol Occup Physiol $1997 ; 75: 212-8$

25 Weyand PG, Smith BR, Puyau MR, et al. The mass-specific energy cost of human walking is set by stature. J Exp Biol 2010;213:3972-9.
26 Cole TJ, Freeman JV, Preece MA. British 1990 growth reference centiles for weight, height, body mass index and head circumference fitted by maximum penalized likelihood. Stat Med 1998;17:407-29.

27 Landing BH, Wells TR, Williamson ML. Anatomy of eccrine sweat glands in children with chronic renal insufficiency and other fatal chronic diseases. Am J Clin Pathol 1970;54:15-21.

28 Meyer F, Bar-Or O, MacDougall D, et al. Sweat electrolyte loss during exercise in the heat: effects of gender and maturation. Med Sci Sports Exerc 1992;24:776-81.

29 Falk B, Bar-Or O, MacDougall JD. Thermoregulatory responses of pre-, mid-, and late-pubertal boys to exercise in dry heat. Med Sci Sports Exerc 1992;24:688???694

30 Inbar O, Morris N, Epstein Y, et al. Comparison of thermoregulatory responses to exercise in dry heat among prepubertal boys, young adults and older males. Exp Physiol 2004;89:691-700.

31 Shibasaki M, Inoue Y, Kondo N, et al. Relationship between skin blood flow and sweating rate in prepubertal boys and young men. Acta Physiol Scand 1999;167:105-10

32 Inoue Y, Ichinose-Kuwahara T, Nakamura S, et al. Cutaneous vasodilation response to a linear increase in air temperature from 28 degrees $C$ to 40 degrees $C$ in prepubertal boys and young men. J Physiol Anthropol 2009;28:137-44.

33 Febbraio MA. Alterations in energy metabolism during exercise and heat stress. Sports Med 2001;31:47-59.

34 Parsons IT, Stacey MJ, Faconti L, et al. Histamine, mast cell tryptase and postexercise hypotension in healthy and collapsed marathon runners. Eur J Appl Physiol 2021;121:1451-9.

35 Ogden HB, Child RB, Fallowfield JL, et al. The gastrointestinal exertional heat stroke paradigm: pathophysiology, assessment, severity, aetiology and nutritional countermeasures. Nutrients 2020;12:537.

36 Flouris AD, Schlader ZJ. Human behavioral thermoregulation during exercise in the heat. Scand J Med Sci Sports 2015;25 Suppl 1:52-64.

37 Bergeron MF, Laird MD, Marinik EL, et al. Repeated-bout exercise in the heat in young athletes: physiological strain and perceptual responses. J App/ Physiol 2009;106:476-85.

38 Abriat A, Brosset C, Brégigeon M, et al. Report of 182 cases of exertional heatstroke in the French armed forces. Mil Med 2014;179:309-14.

39 Stacey MJ, Parsons IT, Woods DR, et al. Susceptibility to exertional heat illness and hospitalisation risk in UK military personnel. BMJ Open Sport Exerc Med 2015; 1:e00055

40 Corbett J, White DK, Barwood MJ, et al. The effect of head-to-head competition on behavioural thermoregulation, thermophysiological strain and performance during exercise in the heat. Sports Med 2018;48:1269-79. 